\title{
A game theoretic approach to repeated foreign body ingestion
}

Between January 2010 and February 2014, a 39-year-old asthmatic woman with borderline personality disorder, posttraumatic stress disorder, and a history of childhood sexual trauma was admitted to our hospital system 61 times for foreign body ingestion. During these hospitalizations, she underwent 62 upper endoscopies. She also required two exploratory laparotomies for surgical retrieval of a pencil fragment and a battery that had become obstructed in the small bowel. She has swallowed pencils, portions of disposable razors, knitting needles, metal nail files, toothbrush handles, plastic pen fragments, hair barrettes, disposable cutlery, and AA batteries. All her admissions occurred late in the evening or on weekends. During the past 4-year time period, she also underwent at least 28 additional upper endoscopies at outside hospitals for intentional foreign body ingestion. The patient was assessed as being at high risk for repeated self-harm. She engaged in cognitive behavioral therapy, dialectical behavioral therapy, and electroconvulsive therapy, but her pattern of repetitive swallowing remained unchanged.

A minority of patients is responsible for the majority of intentional foreign body ingestions with substantial economic burden to hospitals $[1,2]$. The interaction between hospital and patient can be phrased in terms of a nonzero sum game between two adversaries [3,4]. Two strategic options are available to both the hospital and the patient. In $\bullet$ Fig. $1 \mathbf{a}$, the four outcomes associated with the two options available to each adversary are arranged in a two-by-two matrix. Each of the four entries in the matrix contains two numbers. The first number represents the preference ranking of the hospital, and the second number represents the preference ranking of the patient. For instance, in - Fig. 1 a, the upper left entry $-2,+2$ reflects the (negative) loss to the hospital through endoscopy, and the psychological gain experienced by the patient through foreign body ingestion and subsequent medical treatment. The entry $-3,+1$ in the lower left cell represents a worse outcome for the hospital, if the patient is not managed immediately, and higher costs accrue through additional medical adverse events. The adverse events also diminish the patient's gain associated with a more risky and complex medical encounter. As reflected by the upper and lower cells in the right column of Fig. 1 a, without foreign body ingestion, no costs or benefits accrue to hospital and the patient. From the patient's perspective, better outcomes are always achieved by choosing the strategy of foreign body ingestion irrespective of what the hospital subsequently decides. From the hospital's perspective, endoscopy always represents the lesser evil. Therefore, the game between hospital and patient always ends with the outcome of the upper left cell marked in red.

The hospital might consider spending some money on providing the patient with an incentive not to swallow foreign objects. For instance, the hospital may provide the patient with a paid hospital position to alleviate her economic hardship and social isolation, contingent on the condition that she stops swallowing foreign objects. Such a hypothetical scenario is depicted by Fig. $\mathbf{1} \mathbf{b}$ with its changed lower row. If the patient continues to ingest foreign bodies in spite of the incentive, the hospital would lose money from the endoscopy and the wasted incentive. The patient may still experience some psychological benefit from the medical encounter, but would lose her monetary reward. Such outcome is reflected by the $-3,-1$ entry of the lower left cell in the revised game matrix shown in - Fig. 1 b. If the patient accepts the incentive as being equivalent or even better than the endoscopy encounters, the hospital loses some money, but less than with repetitive endoscopy (dependent on the expenditure and type of incentive). Such outcome is reflected by the $-1,+3$ entry of the lower right cell in $\bullet$ Fig. $\mathbf{1}$ b.

From the patient's perspective, overall better outcomes are now associated with a strategy of no foreign body ingestion, provided that the hospital also adheres to its strategy of offering an incentive. The revised game between hospital and patient results in a new steady state marked in red by the outcome of the lower right cell. Using game theory and the principles of

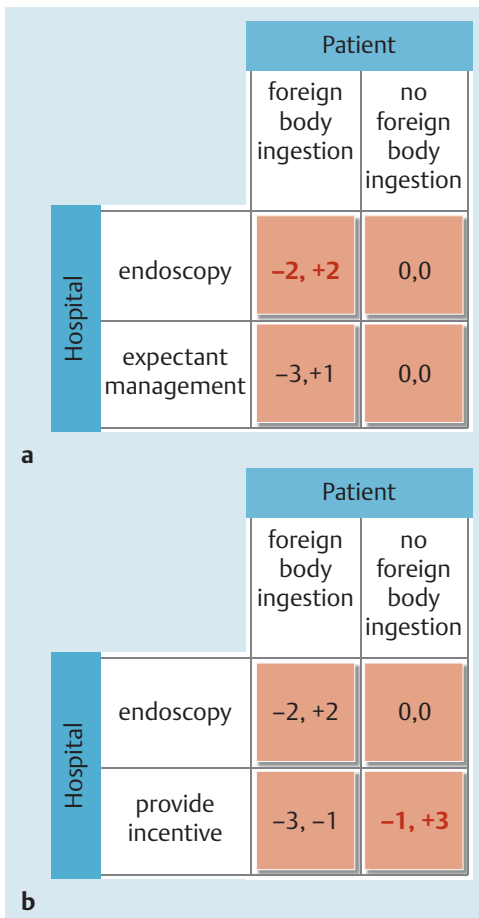

Fig. 1 Game matrix of the interaction between hospital (row player) and patient (column player); a baseline scenario; $\mathbf{b}$ scenario after introduction of incentive.

contingency management, patients with repetitive foreign body ingestion could be offered an incentive to keep them from swallowing foreign objects $[4,5]$.

\section{Endoscopy_UCTN_Code_CCL_1AB_2AF}

Competing interests: None

\section{Sarah J. Diamond, Amnon Sonnenberg}

Portland VA Medical Center and Division of Gastroenterology/Hepatology, Oregon Health \& Science University, Portland, Oregon, USA

\section{References}

1 Frei-Lanter CM, Vavricka SR, Kruger TH et al. Endoscopy for repeatedly ingested sharp foreign bodies in patients with borderline personality disorder: an international survey. Eur J Gastroenterol Hepatol 2012; 24: $793-797$

2 Huang BL, Rich HG, Simundson SE et al. Intentional swallowing of foreign bodies is a recurrent and costly problem that rarely causes endoscopy complications. Clin Gastroenterol Hepatol 2010; 8: 941-946

3 Straffin PD. Game theory and strategy. Washington, DC: The Mathematical Association of America; 1993

4 Sonnenberg A. Personal view: the paradox of runaway competitions in gastroenterology. 
Aliment Pharmacol Ther 2006; 23: 871 878

5 Dutra L, Stathopoulou G, Basden SL et al. A meta-analytic review of psychosocial interventions for substance use disorders. Am Psychiatry 2008; 165: 179-187
Bibliography

Dol http://dx.doi.org/

10.1055/s-0034-1390920

Endoscopy 2015; 47: E79-E80

(c) Georg Thieme Verlag KG

Stuttgart · New York

ISSN 0013-726X
Corresponding author

Amnon Sonnenberg, MD, MSc

Portland VA Medical Center P3-GI

3710 SW US Veterans Hospital Road

Portland

OR 97239

USA

Fax: +1-503-220-3426

sonnenbe@ohsu.edu 